\title{
Implantate in der ästhetischen Zone
}

\author{
Mit diesem Buch schickt der Quintessenz Verlag sein nächstes "Schwergewicht" ins Rennen. \\ Gute vier Kilogramm Papier verteilt auf 835 Seiten warten mit geballtem Wissen auf. Es geht da- \\ bei um Implantate im chirurgisch anspruchsvollsten Einsatzgebiet, dem Frontzahnbereich.
}

Ueli Grunders neues Werk ist ein Meilenstein in der aktuellen Literatur zur Implantologie. Suchen andere Werke wissenschaftliche Legitimation in überbordenden Literaturhinweisen, führt der Autor nur besonders interessante und aufs Wesentliche konzentrierte Quellen an. Ebenfalls minimalistisch fällt die Beschreibung des Instrumentariums und der verwendeten Materialien aus, um dem Leser das Selbstbewusstsein zu vermitteln, dass sich chirurgische Erfolge mit verschiedensten Werkzeugen erreichen lassen und ohnehin dem Patienten, dem Behandler und der Situation angepasst werden müssen.

\section{Erfrischende Neutralität}

Diese bescheidene Herangehensweise beschert dem Buch eine erfrischende Neutralität, welche sich im reinweißen Umschlag spiegelt. Für den klinischen Erfolg, welchen Grunder über den funktionellen Aspekt des „überlebenden Implantats“ hinaus auch in der Ästhetik des benachbarten Weichgewebes definiert, seien vor allem die Techniken und die Einhaltung von chirurgischen Grundprinzipien entscheidend. Der Autor scheut sich nicht, alte Techniken und deren Misserfolge neuen Techniken mit ihren Erfolgen gegenüberzustellen und damit die Grundsätze chirurgischer Arbeit, wie sie sich im Laufe der letzten Jahrzehnte durch praktisch tätige Kollegen herauskristallisierten, zu verdeutlichen.

\section{Rezeptbuch für Implantologen}

Das Buch folgt einem logischen Aufbau, der fast an ein Rezeptbuch erinnert. Die Step-by-Step-Konzepte erlauben es auch dem Anfänger, die beschriebenen Techniken zu verstehen und an- zuwenden. Dabei entspricht die Abfolge der Kapitel genau den notwendigen klinischen Schritten: Grundwissen und Analyse der Ausgangssituation, Extraktion des Zahnes, korrektes Einbringen des Implantates, augmentative Verfahren für Hart- und Weichgewebe, Freilegung sowie die prothetische Versorgung.

Zur Abrundung schließt das Buch mit verschiedenen Fallbeispielen, in denen Schritt für Schritt noch einmal die vorgestellten Techniken zusammengefasst werden, sodass der Gesamtablauf einer erfolgreichen Implantatbehandlung praktisch greifbar wird. Der didaktisch einfach gehaltene Fließtext wird durch sensationelle Bildreihen und sinnvolle schematische Darstellungen ergänzt, womit das Ziel des Buches erreicht wäre: Der Leser soll nicht nur zusehen, sondern verstehen.

Wenn Implantologie doch nur immer so einfach wäre.

Moritz Etges

\begin{tabular}{|c|c|}
\hline & Implantate in der ästhetischen Zone \\
\hline verement & Ein Behandlungskonzept step by step \\
\hline $\begin{array}{l}\text { IMPLANTATE } \\
\text { IN DER } \\
\text { ÄSTHETISCHEN } \\
\text { ZONE }\end{array}$ & $\begin{array}{l}\text { Autor: Ueli Grunder } \\
\text { 1. Auflage } 2015 \\
\text { Hardcover, } 848 \text { Seiten, } 4.049 \text { Abbildungen } \\
\text { Quintessenz Verlags-GmbH } \\
\text { ISBN 978-3-86867-244-2 } \\
\text { Preis: } 320 \text { Euro }\end{array}$ \\
\hline
\end{tabular}

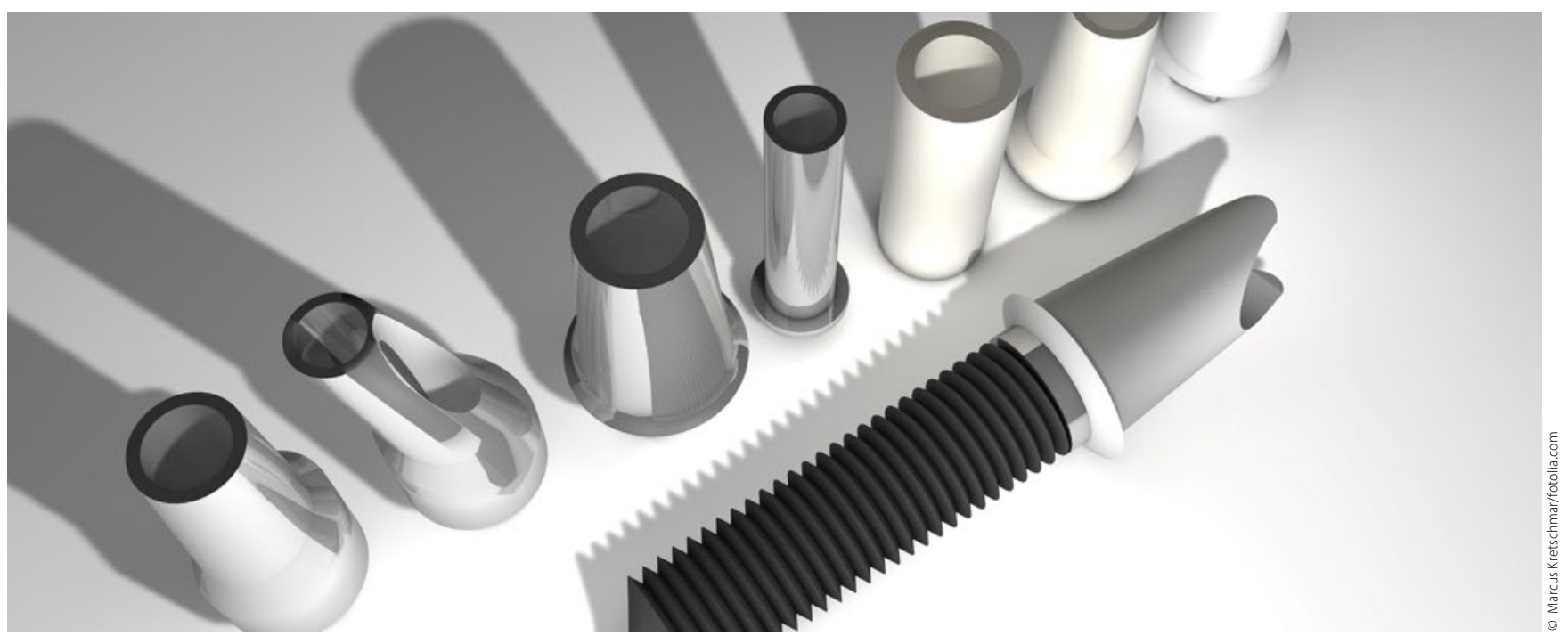

